\title{
Immunohistochemical Profile of Endometrial Adenocarcinoma: A Study of 61 Cases and Review of the Literature
}

\author{
Sophia Kounelis, M.D., Nikiforos Kapranos, M.D., Efi Kouri, M.D., Domenico Coppola, M.D., \\ Helen Papadaki, M.D., Mirka W. Jones, M.D. \\ Department of Pathology, Helena Venizelou Women's Hospital (SK, EK) and Amalia Flemming Hospital \\ (NK), Athens, Greece; Department of Pathology, H. Lee Moffitt Cancer Center, University of South Florida \\ (DC), Tampa, Florida; Patras General Hospital (HP), Patras, Greece; Department of Pathology, Magee- \\ Women's Hospital, University of Pittsburgh (MWJ), Pittsburgh, Pennsylvania
}

The differences in immunohistochemical expression of p53, bcl-2, bax, estrogen receptor (ER), and progesterone receptor (PR) were evaluated in 40 endometrioid and 21 papillary serous carcinomas of endometrium and correlated with known predictors of survival, such as grade and stage. Uterine papillary serous adenocarcinomas (UPSA) showed significantly higher p53 expression than did uterine endometrioid adenocarcinomas (UEA) $(76.2 \%$ versus 35\%), whereas both ER and PR were more often positive in endometrioid than in serous tumors ( $p=$ .005 and .0005). No significant difference was found in bcl-2 and bax expression between both histologic types. However, there was definite decrease in intensity of bcl-2 in UPSA compared with UEA. In endometrioid carcinoma, p53 overexpression was associated with high-grade and advanced-stage tumors ( $p=.0006$ and .006), whereas ER and PR expression was associated with low-grade and earlystage tumors $(p=.0006$ and $.0001 ; p=.003$ and .0006). Bcl-2 immunopositivity was more common in low-grade, early-stage rather than in high-grade, advanced-stage adenocarcinomas, but the difference was not statistically significant ( $p=.24$ and .07). Bax immunopositivity was associated with well-differentiated $(p=.04)$ and early-stage tumors. Furthermore, a significant inverse relationship between bax and $\mathrm{p} 53$ reactivity was defined $(p=.05)$, especially in tumors of endometrioid type. Bax and PR immunoexpression correlated near the limit of statistical significance $(p=.08)$, whereas no relationship was found among bax, bcl-2, and ER

Copyright (C) 2000 by The United States and Canadian Academy of Pathology, Inc.

VOL. 13, NO. 4, P. 379, 2000 Printed in the U.S.A.

Address reprint requests to: Mirka W. Jones, M.D., Department of Pathology, Magee-Women's Hospital, 300 Halket Street, Pittsburgh, PA 15213; fax: 412-641-1675. immunopositivity. Our results indicate that the differences in immunohistochemical profiles of endometrioid and serous carcinomas support the existence of different molecular pathways of their development. The correlation of immunohistochemical findings with histologic grade and clinical stage could help in predicting biologic behavior and planning treatment in patients who are diagnosed as having these tumors.

KEY WORDS: bax, bcl-2, Endometrial adenocarcinoma, Endometrioid, Papillary serous, p53.

Mod Pathol 2000;13(4):379-388

Endometrial adenocarcinoma (EA) is the most common gynecologic malignancy (1). Traditional factors associated with its prognosis include patient's age, tumor grade, stage, histologic type, and the depth of myometrial invasion. Two histologic types of EA-endometrioid and papillary serousare associated with different biologic behavior (2, 3). Uterine endometrioid adenocarcinomas (UEA) are usually accompanied by endometrial hyperplasia and typically are low grade, are early stage, and have favorable prognosis. Uterine papillary serous adenocarcinomas (UPSA) usually develop in an atrophic endometrium; are high grade; are advanced stage, and do not respond to conventional chemotherapy, radiotherapy, and hormone therapy $(4,5)$. Recently, a dualistic model of carcinogenesis has been proposed on the basis of the distinctive clinical and histologic features of endometrioid and serous adenocarcinoma (6). Based on this model, UEA is associated with a slow, estrogen-driven model of carcinogenesis whereby unopposed estrogen stimulation leads to the sequential malignant transformation through a stage of atypical endometrial hyperplasia. In contrast, a p53-driven model of 
carcinogenesis is responsible for the rapid development and progression of UPSA (7).

Cancer development and growth are associated with the deregulation of cell proliferation as well as programmed cell death or apoptosis. p53 is a tumor suppressor gene located on the short arm of chromosome 17 (8). Wild type p53 protein contributes to tumor suppression through both arrest of cell proliferation and induction of cell death through apoptosis $(9,10)$. Inactivation of p53 function through allelic loss, mutation, or complex formation with other nuclear proteins contributes to malignant transformation. This process makes malignant cells more resistant to cytotoxic chemotherapeutic drugs and radiation because of failure in induction of apoptosis (11). Although p53 is one of the most commonly mutated genes in human tumors (12), the molecular and immunohistochemical investigation of p53 expression in endometrial cancer is contradictory and its role remains to be defined.

Bcl-2 and related proteins are some of the most important regulators of programmed cell death or apoptosis. The bcl-2 gene was first described in non-Hodgkin's lymphoma as a result of its involvement in the $t(14 ; 18)$ chromosomal translocation (13). Subsequently, bcl-2 was reported in many other tumors, including carcinomas of the breast, prostate, and lung (14-16). Bcl-2 protein functions at least in part through interactions with other members of the bcl-2 protein family that share homology with its molecule. One of them is bax, a 21 KDa protein that shares approximately $21 \%$ homology with bcl-2 and promotes apoptosis (17). Bax can produce heterodimers with bcl-2 or homodimers with itself. It has been proposed that bcl-2 suppresses cell death through its heterodimerization with bax. Bcl-2/bax heterodimers suppress programmed cell death, whereas bax/bax homodimers promote it. Thus, the ratio of bcl-2/ bax heterodimers to bax/bax homodimers has been hypothesized to function as a kind of intracellular rheostat to control apoptosis (18). In addition, p53 interferes in this setting as a suggested transcriptional activator of bax as well as a negative transregulator of the $b c l-2$ gene $(19,20)$. There are conflicting reports on the significance of bcl-2 expression in EA, whereas, to the best of our knowledge, no data are available on the expression of bax in endometrial tumors.

The goals of this study were 3 fold: to evaluate the differences in the immunohistochemical expression of p53, bcl-2, bax, estrogen receptor (ER), and progesterone receptor $(\mathrm{PR})$ in endometrioid and serous carcinoma, to correlate the results with tumor grade and stage, and to study the relationship of bax with other immunohistochemical markers.

\section{MATERIALS AND METHODS}

\section{Subjects}

Sixty-one nonconsecutive hysterectomy specimens that contained EA and were collected between 1986 and 1994 were selected from the files of the Department of Pathology of Magee-Women's Hospital, University of Pittsburgh Medical Center. The tumors had been classified according to histologic type into two main categories-endometrioid and papillary-serous - and had been graded and staged following the current recommendations of the International Federation of Gynecology and Obstetrics. Endometrioid-type carcinomas were composed of glands (architectural Grade 1), a combination of glands and masses of solid epithelium (architectural Grade 2), or predominantly solid proliferations (architectural Grade 3). The nuclear grade was evaluated separately and classified as 1 , mild nuclear atypia (slight variation in size and shape, evenly distributed chromatin, inconspicuous nucleoli); 2, moderate nuclear atypia (moderate variation in size and shape, some chromatin clumping, single nucleolus); and 3, severe nuclear atypia (pleomorphism, enlargement, hyperchromatism, irregular coarse chromatin clumping, and prominent eosinophilic nucleoli). The combined grade was obtained by adding 1 to the grade of tumors with architectural Grade 1 or 2 if they displayed severe, Grade 3 nuclear atypia. Serous carcinomas consisted of predominantly papillary proliferations, with admixture of solid and glandular patterns. Tumor cells were loosely cohesive cuboidal or hobnail-shaped with severe nuclear atypia. In cases of serous carcinomas with prominent glandular pattern and endometrioid carcinomas with prominent papillary pattern, the classification was based on nuclear grade. The glands and papillary formations in endometrioid carcinomas were lined by epithelium with Grade 1 or 2 nuclei, whereas serous carcinomas always displayed Grade 3 nuclei. Hematoxylin-eosin stained sections from each case were reviewed, and representative sections from each tumor were selected. The clinical information, including patients' age and clinical stage, was obtained from the Magee-Women's Hospital Tumor Registry.

\section{Immunohistochemistry}

Four-micron-thick representative tissue sections were immunohistochemically stained for p53, bcl-2, bax, ER, and PR using a combination of the avidin-biotin complex peroxidase method (ABC kit; Vector Laboratories, Burlingame, CA) and microwave antigen retrieval ( $15 \mathrm{~min}-0.01 \mathrm{~N}$ citrate buffer, $\mathrm{pH}$ 6). The antibody used for the detection of p53 was a mouse, antihuman monoclonal antibody, 
clone D07 (DAKO, Nutley, NJ; dilution, 1:50, 45 min), designed to recognize an epitope in the $\mathrm{N}$-terminal region, thus detecting elevated levels of both wild type and mutant protein. The primary antibodies used for the detection of the bcl- 2 and bax products were a mouse antihuman monoclonal antibody (clone 124; DAKO, Copenhagen, Denmark; dilution 1:50, overnight $40^{\circ} \mathrm{C}$ ) and a rabbitantihuman polyclonal antibody (Pharmingen, San Diego, CA; dilution, 1:1000, overnight $40^{\circ} \mathrm{C}$ ), respectively. To detect ER and PR, the tissue sections were incubated with monoclonal mouse antibodies, clones ID5 and 1A6, respectively (Biogenex, San Ramon, CA; dilution, 1:20, $2 \mathrm{~h}$ at room temperature). Appropriate positive controls were performed at the same time (Table 1) while tissue sections in which the primary antibody was omitted were used as negative controls.

\section{Scoring and Statistical Analysis}

The stained slides were microscopically analyzed by two independent observers. Specimens were considered immunopositive when a cutoff value of $10 \%$ or more of the neoplastic cells showed clear evidence of nuclear immunostaining for p53 and cytoplasmic staining for bcl-2 and bax. The evaluation of ER and PR was performed according to the method described by Carcangiu et al. (21) Based on the percentage of stained cells and the intensity of nuclear stain. The percentage of positive cells was graded as follows: 1,0 to $25 \%$ of the nuclei stained; 2,26 to $75 \%$ of nuclei stained; 3 , more than $76 \%$ of the nuclei stained. The staining intensity was scored as follows: 1 , absent or weak; 2, strong; and 3 , very strong. The sum of both parameters gave the immunohistochemical score. Tumors were divided into three categories depending on the immunohistochemical score. Category I corresponded to a score of 2, Category II to a score of 3 or 4 , and Category III to a score of 5 or 6 . Category I tumors were considered as immunonegative, whereas Category II and III tumors were considered as immunopositive.

$\chi^{2}$ statistics were used to test for correlations. Statistical significance was considered achieved when the $p$ value was less than or equal to 0.05 . All statistical analyses were performed using the statis- tical program Statistica: basic statistics (StatSoft, Tulsa, OK).

\section{RESULTS}

\section{Clinicopathologic Findings}

Sixty-one tumors were evaluated: 40 endometrioid carcinomas and 21 papillary serous or mixed papillary serous endometrioid carcinomas. The average age at presentation for UEA and UPSA was $64.5 \mathrm{y}$ and $69.6 \mathrm{y}$, respectively, and although women with endometrioid carcinoma were approximately 5 y younger on average than women with serous carcinoma, this difference was not statistically significant. Twenty-seven UEA were low grade (Grades 1 and 2), and 13 were high grade (Grade 3). Twenty patients presented with early-stage tumors (Stage IA to IIB), and 20 presented with advanced-stage tumors (IIIA to IVB). All UPSA were Grade 3, and the majority of patients presented with advanced-stage tumors (18 of 21). Thus, the statistical correlation of immunohistochemical results with grade and stage was not possible with this group.

\section{Immunohistochemical Findings}

Of the 61 tumors, 30 (49\%) showed positive immunoreactivity for p53, 40 (65.6\%) for bcl-2, 28 (46\%) for bax, 33 (54\%) for ER, and 33 (54\%) for PR. P53 and ER-PR immunostaining was confined to the nucleus, whereas bcl-2 and bax immunostaining was localized in the cytoplasm. Some bcl-2positive cells displayed a characteristic perinuclear intensity.

P53 immunostaining was stronger and more diffuse in UPSA than in UEA (Fig. 1). Both the intervening stroma and the adjacent benign endometrium (proliferative or hyperplastic with or without atypia) were negative for p53, whereas p53 immunoreactivity extended to the adjacent atrophic epithelium in one papillary serous carcinoma. UEA showed stronger and more uniform staining for bcl-2 than did UPSA (Fig. 2), although the positivity rate was similar between these two subtypes. Bcl-2 also stained normal endometrial stroma and myometrium, and the staining was usually stronger and more uniform in normal tissues than in carcino-

TABLE 1. Antibodies Used for Immunohistochemical Staining

\begin{tabular}{|c|c|c|c|}
\hline Antigens & Antibodies & Dilution & Controls \\
\hline p53 & Mouse antihuman monoclonal (D07; DAKO, Nutley, NJ) & $1: 50$ & Human ductal carcinoma of breast \\
\hline $\mathrm{Bcl} 2$ & $\begin{array}{l}\text { Mouse antihuman monoclonal (clone 124; DAKO, Copenhagen, } \\
\text { Denmark) }\end{array}$ & $1: 40$ & Normal human lymph node \\
\hline Bax & Rabbit antihuman polyclonal (Pharmingen, San Diego, CA) & $1: 1000$ & Normal human lymph node \\
\hline ER & Mouse monoclonal ( $1 \mathrm{D}_{5}$, Biogenex, San Ramon, CA) & $1: 20$ & Human ductal carcinoma of breast \\
\hline PR & Mouse monoclonal $\left(1 \mathrm{~A}_{6}\right.$, Biogenex $)$ & $1: 20$ & Human ductal carcinoma of breast \\
\hline
\end{tabular}

ER, estrogen receptor; PR, progesterone receptor. 


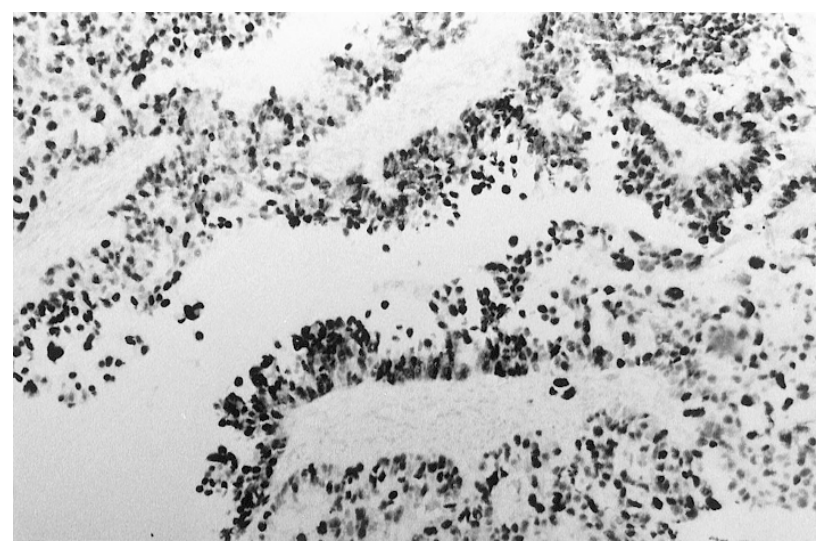

FIGURE 1. Strong and diffuse p53 nuclear immunostaining in uterine papillary serous adenocarcinoma.

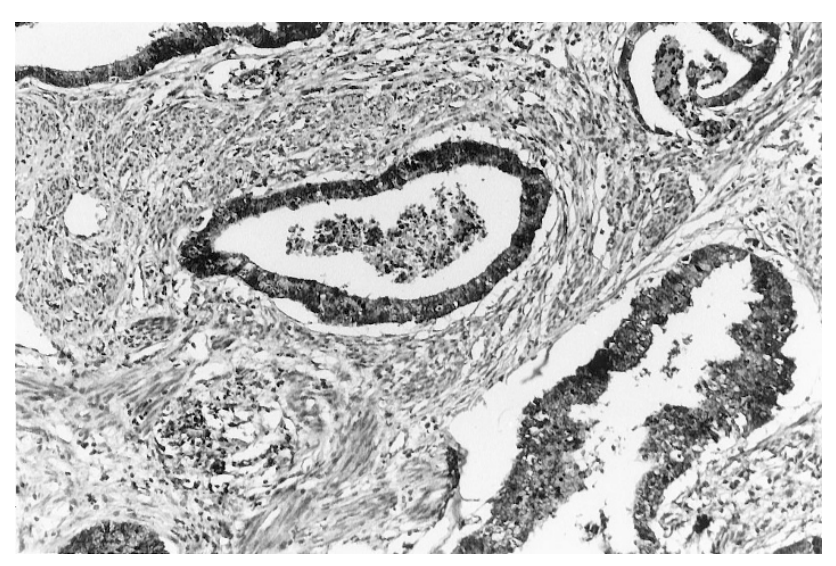

FIGURE 2. Strong cytoplasmic bcl-2 immunostaining in low-grade uterine endometrioid adenocarcinoma.

mas. Bax immunopositivity was present in the myometrium, in the wall of the myometrial vessels, in the endometrial stroma, and in the cytoplasm of the adjacent normal endometrial glands proliferative, atrophic, or hyperplastic. In both types of endometrial carcinoma, bax immunoreactivity was similar (Figs. 3A and B) and usually less intense and more heterogeneous than in normal endometrium. Bax positivity was characteristically absent in the areas of squamous differentiation (Fig. 3C). In some neoplastic cells, the cytoplasmic staining was characteristically granular and subnuclear in location (Fig. 3D).

Table 2 summarizes the results of the immunohistochemical staining in both types of EA. Fourteen of 40 UEA (35\%) and 16 of 21 UPSA (76.2\%) displayed p53 protein overexpression with a significant difference ( $p=.003$ ) between the two histologic types. Both ER expression and PR expression were significantly higher in UEA ( $p=.005$ and .0005) than in UPSA (Fig. 4), whereas no difference was found regarding bcl-2 and bax positivity in both types.

Table 3 summarizes the correlation of immunohistochemical staining and tumor grade in EA. P53 overexpression was more often associated with high-grade tumors ( $p=.0006)$, whereas bax, ER, and PR expression was more common in low-grade tumors ( $p=.04, .0006$, and .003). Bcl-2 immunoreactivity was also more common in low-grade tumors, but this difference was not statistically significant. According to Table 4, p53 immunopositivity was more common in advanced- rather than earlystage endometrial carcinoma (55\% versus $15 \%$; $p=$ .006), whereas ER and PR were more often associated with early-stage tumors ( $p=.0001$ and .0006). Both bcl-2 and bax were more often present in early- rather than advanced-stage tumors, but the difference was not statistically significant.

Table 5 summarizes the correlation between bax and p53, bcl-2, ER, and PR immunoreactivity in EA. There is a statistically significant inverse relationship between bax and p53 ( $p=.05)$, more significant in carcinomas of endometrioid than serous type ( $p=.01)$. This finding is consistent with the fact that the absence of p53 immunoreactivity correlates with the presence of normal wild type p53 protein that induces bax expression. Bax positivity correlated with PR positivity near the limit of statistical significance $(p=.08)$, whereas no relationship was found among bax, bcl-2, and ER expression.

\section{DISCUSSION}

The results of multiple studies that investigated the molecular and genetic alterations in endometrial carcinogenesis have often been controversial and reflect the complexity and diversity of this process. EA comprises a morphologically heterogeneous group that includes tumors composed of glands resembling normal endometrium (endometrioid type) and tumors that arise in the extended Müllerian system, such as papillary serous carcinomas or clear cell carcinomas.

A large number of EA express ER and PR (22). Therefore, the absence of ER and PR expression may be an important finding in the process of advancement of endometrial carcinogenesis (23). In addition, as in other neoplasms, tumor growth and progression depend on the alterations of oncogenes and tumor suppressor genes that most likely accumulate during a multistage process and cause the imbalance between proliferation and programmed cell death or apoptosis (24). Three genes involved in the regulation of cell cycle and apoptosis investigated in the current study are $p 53, b c l-2$, and bax.

The overall rate of p53 positivity in our study was $49 \%$. Almost two thirds of our cases were of either high grade or advanced stage (Stage III and IV), which is consistent with previous reports that described p53 positivity as approximately 10 to $15 \%$ in 

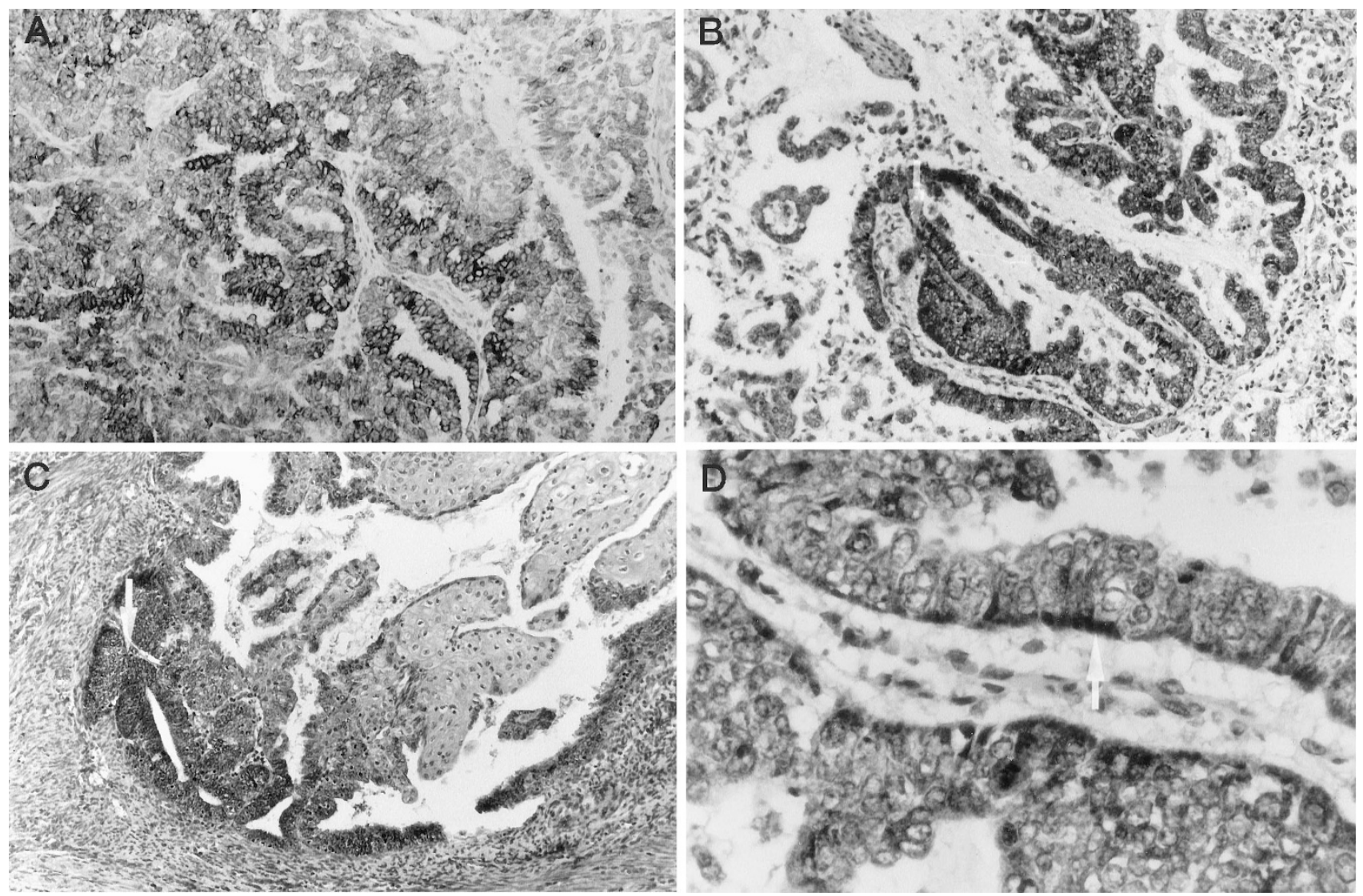

FIGURE 3. A, moderate bax immunostaining in uterine endometrioid adenocarcinoma (UEA). B, strong bax immunostaining in uterine papillary serous adenocarcinoma. C, absence of bax immunostaining in the area of squamous differentiation in a bax immunopositive UEA case. D, strong subnuclear cytoplasmic bax immunostaining in UEA.

TABLE 2. p53, bcl-2, bax, ER, and PR Expression According to Histologic Type in Endometrial Adenocarcinoma

\begin{tabular}{|c|c|c|c|c|c|c|}
\hline $\begin{array}{c}\text { Histologic } \\
\text { Type }\end{array}$ & $\begin{array}{c}\text { No. } \\
\text { Cases }\end{array}$ & $\begin{array}{c}\text { p53+ } \\
\text { No. (\%) }\end{array}$ & $\begin{array}{l}\text { bcl-2+ } \\
\text { No. (\%) }\end{array}$ & $\begin{array}{c}\text { bax }+ \\
\text { No. (\%) }\end{array}$ & $\begin{array}{c}\mathrm{ER}^{+} \text {No. } \\
(\%)\end{array}$ & $\begin{array}{c}\mathrm{PR}^{+} \\
\text {No. (\%) }\end{array}$ \\
\hline UEA & 40 & $14(35)$ & $26(65)$ & $19(47.5)$ & $28(70)$ & $29(72.5)$ \\
\hline UPSA & 21 & $\begin{array}{l}16(76.2) \\
p=.003\end{array}$ & $\begin{array}{c}14(66.5) \\
p=.80\end{array}$ & $\begin{array}{c}9(43) \\
p=.56\end{array}$ & $\begin{array}{r}5(23.8) \\
p=.005\end{array}$ & $\begin{array}{c}4(19) \\
p=.0005\end{array}$ \\
\hline
\end{tabular}

ER, estrogen receptor; PR, progesterone receptor; UEA, uterine edometrioid adenocarcinoma; UPSA, uterine papillary serous adenocarcinoma.

early- and 40 to $52 \%$ in advanced-stage EA (25-27). Also, as in previous studies, p53 positivity was significantly higher in papillary serous than in endometrioid carcinomas $(6,7,28-36)$. The high rate of p53 positivity found in UPSA $(76.2 \%)$ could be compared only with that reported for uterine carcinosarcomas that share the same aggressive behavior (37). The difference in p53 overexpression between the two histologic types disappeared, however, when UPSA and UEA were matched by nuclear grade (Grade 3 UEA 69\% versus UPSA $76.2 \%$ ). This finding is in agreement with the study of Zheng et al. (28) as well as with similar correlations of p53 positivity with high nuclear grade in infiltrating duct carcinoma of the breast (38). The difference in p53 expression in the two types of EA includes not only the percentage of p53-positive tumors but also the cause and timing of p53 alterations. In UPSA, p53 protein overexpression correlates closely with the presence of p53 mutations and the loss of p53 function (35). In UEA, p53 protein accumulation can occur without a detectable gene mutation because 21 to $52 \%$ show p53 positivity $(26,27)$ but only 14 to $23 \%$ contain p53 mutation $(26,39,40)$. A possible explanation for the phenomenon of p53 expression without mutation in UEA is a posttranscriptional conformational change of the wild type protein that might occur if the molecule underwent complex formation with other nuclear proteins, such as mdm-2 $(41,42)$. A selective correlation of mdm-2 expression with p53 expression in UEA was previously reported, whereas such a correlation was not found in UPSA (42). The absence of p53 alterations in atypical hyperplasia and significantly higher p53 immunopositivity in high-grade and advanced-stage UEA in the current study sup- 

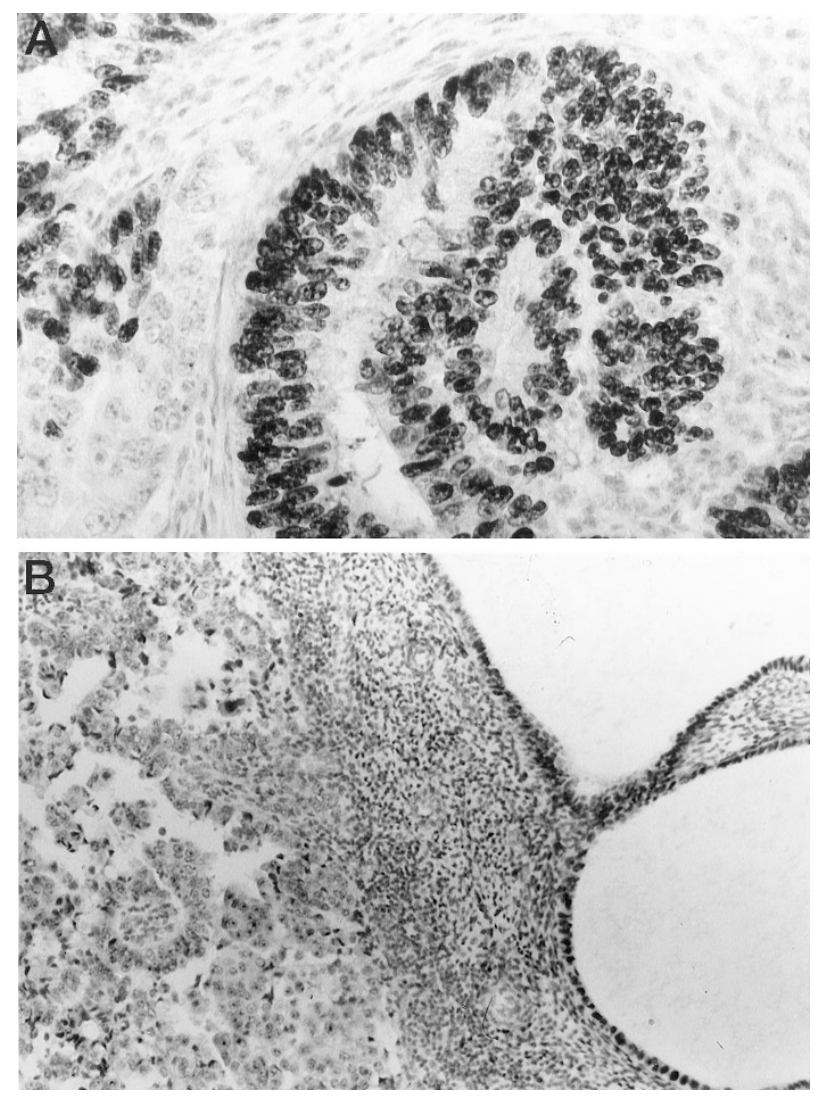

FIGURE 4. A, strong nuclear estrogen receptor immunostaining in uterine endometrioid adenocarcinoma. B, absence of estrogen receptor immunostaining in uterine papillary serous adenocarcinoma. Note estrogen receptor immunopositivity in surrounding atrophic endometrium.

port the late occurrence of p53 alterations in the pathogenesis of endometrioid tumors $(26,29,32$, $33,43-47)$. In serous tumors, the reported identification of p53 overexpression and gene mutation in endometrial intraepithelial carcinoma, a recently identified precursor of UPSA $(48,49)$ as well as in early-stage UPSA (28), support the early occurrence of p53 alterations. In our study, there was extension of p53 immunoreactivity to the adjacent atrophic atypical endometrial glands in one of the diffusely immunopositive UPSA and the accumulation of p53 protein in a very small superficially invasive UPSA arising in an endometrial polyp.

The bcl-2 proto-oncogene encodes a protein that determines whether a cell will proceed to apoptosis or remain viable. The bcl-2 protein blocks apoptosis induced by several stimuli without affecting cell proliferation. The other proteins that belong to the bcl-2 family include bax, bcl-x, bad, bak, Al, and mcl-1. Among these, bax has a critical role in apoptosis because of its ability to homodimerize with itself or heterodimerize with bcl-2. In particular, bax homodimer promotes apoptosis, whereas bax/ bcl-2 heterodimer inhibits it. The wild type p53 protein is related to this family by counteracting the action of bcl-2 and acting as a transcriptional acti- vator of bax (19). Consequently, mutant or inactivated p53, like bcl-2, blocks apoptosis. Cyclical expression of the bcl-2 protein has been demonstrated in the normal endometrium during the menstrual cycle and seems to be under hormonal control (52). In the present study, normal (proliferative and hyperplastic) endometrium adjacent to tumor showed strong and homogeneous staining, stronger in the majority of cases than the tumor itself. This is consistent with previous studies according to which bcl-2 is strongly expressed in the estrogen-dependent proliferative endometrium and becomes progressively weaker in hyperplastic endometrium and endometrial carcinoma (52-54). Bcl-2 overexpression in more than $10 \%$ of tumor cells was found in $65.6 \%$ of the 61 examined carcinomas, whereas the rates reported in the literature range widely from 34 to $85 \%(28,55-57)$. Although no difference was noted in the frequency of bcl-2 expression in UEA and UPSA (65 versus 66.5\%), UPSA showed less intense and more heterogeneous expression of this marker than did UEA. In agreement with this observation are the reports of Niemann et al. (58) and Zheng et al. (28). Although bcl-2 expression in the current study was more frequent in low-grade endometrioid carcinomas, this difference was not statistically significant. Most of the previous reports showed higher incidence of bcl-2 positivity in well-differentiated tumors, but some found no association between bcl-2 expression and histologic grade $(55,58)$. In our study, bcl-2 expression was also associated with earlystage endometrioid tumors (75 versus $55 \%$ ) and the difference was very close to the limit of statistical significance ( $p=.07)$. Conflicting results have been reported in the literature regarding this issue $(28$, 54-58). The discrepancy of bcl-2 staining in different grades and stages of endometrial carcinoma between studies is most likely the result of a number of factors, including the relative antibody sensitivity, the different immunohistochemical techniques, the difference in patient selection, and the different thresholds for bcl-2 positivity. Thus, it is important for investigators to establish similar methodologies to understand fully the complex role of bcl-2 in the initiation and progression of tumors. The reduction of bcl-2 immunoreactivity from proliferative endometrium to endometrial carcinoma and from early- to advanced-stage EA suggests that the role of bcl-2-related apoptosis is less important in advanced-stage endometrial carcinoma. It seems likely that, in early stages, tumors with bcl-2-positive long-lived cells may have more chance to accumulate other gene abnormalities for further malignant transformation. Once transformed cells acquire malignant phenotypes, bcl-2 protein does not play an important role anymore and may be 
TABLE 3. p53, bcl-2, bax, ER, and PR Expression According to Tumor Grade in Uterine Endometrioid Adenocarcinoma

\begin{tabular}{|c|c|c|c|c|c|c|}
\hline Grade & $\begin{array}{c}\text { No. } \\
\text { Cases }\end{array}$ & $\begin{array}{c}\text { p53+ } \\
\text { No. (\%) }\end{array}$ & $\begin{array}{c}\text { bcl-2+ } \\
\text { No. (\%) }\end{array}$ & $\begin{array}{c}\text { bax }+ \\
\text { No. (\%) }\end{array}$ & $\begin{array}{c}\text { ER }^{+} \\
\text {No. }(\%)\end{array}$ & $\begin{array}{c}\mathrm{PR}^{+} \\
\text {No. (\%) }\end{array}$ \\
\hline $\operatorname{Low}^{a}$ & 27 & 5 (18.5) & $19(70.4)$ & 15 (55.6) & 24 (88.8) & $23(85.2)$ \\
\hline $\operatorname{High}^{b}$ & 13 & $\begin{array}{c}9(69) \\
p=.0006\end{array}$ & $\begin{array}{c}7(53.2) \\
p=.24\end{array}$ & $\begin{array}{c}4(30.8) \\
p=.04\end{array}$ & $\begin{array}{c}4(30.8) \\
p=.0006\end{array}$ & $\begin{array}{r}6(46.2) \\
p=.003\end{array}$ \\
\hline
\end{tabular}

ER, estrogen receptor; PR, progesterone receptor.

a Grades 1 and 2.

${ }^{b}$ Grade 3 .

TABLE 4. p53, bcl-2, bax, ER, and PR Expression According to Tumor Stage in Uterine Endometrioid Adenocarcinoma

\begin{tabular}{|c|c|c|c|c|c|c|}
\hline Stage & $\begin{array}{c}\text { No. } \\
\text { Cases }\end{array}$ & $\begin{array}{c}\text { p53+ } \\
\text { No. }(\%)\end{array}$ & $\begin{array}{c}\text { bcl-2+ } \\
\text { No. (\%) }\end{array}$ & $\begin{array}{c}\text { bax }+ \\
\text { No. (\%) }\end{array}$ & $\begin{array}{c}\text { ER }^{+} \\
\text {No. (\%) }\end{array}$ & $\begin{array}{c}\mathrm{PR}^{+} \\
\text {No. (\%) }\end{array}$ \\
\hline Early $^{a}$ & 20 & 3 (15) & $15(75)$ & $11(55)$ & $20(100)$ & $20(100)$ \\
\hline Advanced $^{b}$ & 20 & $\begin{array}{c}11(55) \\
p=.006\end{array}$ & $\begin{array}{l}11(55) \\
p=.07\end{array}$ & $\begin{array}{c}8(40) \\
p=.40\end{array}$ & $\begin{array}{c}8(40) \\
p=.0001\end{array}$ & $\begin{array}{c}9(45) \\
p=.0006\end{array}$ \\
\hline
\end{tabular}

${ }^{a}$ Stages IA to IIB.

${ }^{b}$ Stages IIA to IVB.

TABLE 5. Correlation Between bax Reactivity and p53, bcl-2, ER, and PR Reactivity in Endometrial Adenocarcinoma

\begin{tabular}{cccc}
\hline & $\begin{array}{c}\text { Bax+ No. } \\
\text { Cases }\end{array}$ & $\begin{array}{c}\text { Bax- No. } \\
\text { cases }\end{array}$ & $p$ \\
\hline $\mathrm{p} 53$ & 10 & 20 & 0.05 \\
+ & 18 & 13 & \\
- & & & 0.35 \\
$\mathrm{bcl}-2$ & 17 & 23 & \\
+ & 11 & 10 & 0.37 \\
- & & 17 & \\
ER & 16 & 16 & 0.08 \\
+ & 12 & 14 & \\
- & & 18 & \\
PR & 18 & 10 &
\end{tabular}

ER, estrogen receptor; PR, progesterone receptor.

inactivated by cellular mechanisms that modify and decrease its expression.

The distribution of bax, to our knowledge, has never been reported in the human uterus, and the only data available describe its expression in female mice (59). In the current study, we detected strong bax immunoactivity in the myometrium, including the walls of the myometrial vessels, as well as in proliferative, atrophic, or hyperplastic endometrium. Bax positivity was always stronger in normal tissues than in EA. These results are similar to bax positivity in esophageal, prostate, gastric, and breast carcinomas, whereas in colorectal adenomas and carcinomas, bax expression was stronger than in the normal colonic mucosa (60-65). Twentyeight of 61 examined tumors showed bax overexpression in more than $10 \%$ of the neoplastic cells, and there was no difference between UEA and UPSA. Bax overexpression was significantly associated with well-differentiated endometrioid carcinomas. Early-stage endometrioid tumors also expressed bax more frequently than did advanced stage, but the difference was not statistically signif- icant. The reduced incidence of bax expression in high-grade and advanced-stage endometrioid tumors in this series can be explained in part by an inverse relationship between bax and p53 hyperexpression. It has been previously described that the bax gene promoter contains four consensusbinding site sequences for the tumor suppressor p53. Furthermore, only wild but not mutant p53 can transactivate the bax gene promoter (19). Consequently, a more common p53 expression in highgrade and advanced-stage EA may result in a reduced expression of bax protein in these tumors. In contrast, other tumors, such as breast carcinoma, do not show this correlation, suggesting that p53 is not a dominant regulator of bax expression in their development (63). In addition, this study showed a positive correlation between bax and PR expression, which again is in discordance with the results of similar correlations in breast cancer 63). Finally, no correlation between the expression of the antiapoptotic bcl-2 protein and the proapoptotic bax protein was noted, compared with an inverse correlation between these proteins found in esophageal and neuroendocrine lung tumors $(60,66)$. Bcl-2, however, is not the only antiapoptotic member of the bcl-2 family, and it would be interesting to investigate the association of bax expression with any other antiapoptotic members, such as bcl-XL and Mcl-1, to define the significance of their interaction with the bax protein.

Endometrioid carcinomas are regarded as "sex steroid dependent" tumors that often express ER and PR. In the current study, both ER and PR positivity was observed in 54\% of 61 carcinomas. This rate, although low as compared with that reported in the literature $(70 \%)$, can be explained by the predominance of high-grade and advanced-stage tumors. ER and PR status was significantly associated with endometrioid type ( $p=.005$ and .0005), 
and their expression in UPSA was only $24 \%$ and $19 \%$, respectively. This finding correlates with the majority of the previous studies, although data concerning hormone receptor expression in USPA are conflicting $(21,67,68)$. Initial results of biochemical assays performed on tissue homogenates suggested that serous carcinomas possessed ER and PR (4). However, the subsequent immunohistochemical studies indicated that the receptor protein was not localized on the tumor cells and suggested that biochemical assays might yield false-positive results because of contamination by normal endometrium and myometrium $(67,69)$. The absence of sex steroid receptors in UPSA is also supported by the lack of response of these tumors to progestational therapy. ER and PR expression in endometrioid carcinoma was significantly associated with both welldifferentiated ( $p=.0006$ and .003) and early-stage ( $p=.0001$ and .0006) tumors. All early-stage endometrioid carcinomas were positive for both ER and PR. The majority of published studies showed similar results (70-72).

In conclusion, the different immunohistochemical profiles of endometrioid and papillary serous carcinomas confirm different molecular pathways in their development and support their designation as separate entities. However, further wellcontrolled studies are needed before a potential impact of this information can help in planning treatment and predicting prognosis.

\section{REFERENCES}

1. Gurpide E. Endometrial cancer: biochemical and clinical correlates. J Natl Cancer Inst 1991;83:405-16.

2. Deligdisch L, Holinka CF. Endometrial carcinoma: two diseases? Cancer Detect Prev 1987;10:237-46.

3. Hendrikson M, Bass J, Eifel P, Martinez A, Kempson R. Uterine papillary serous adenocarcinoma: a highly malignant form of endometrial adenocarcinoma. Am J Surg Pathol 1982;6:93-108.

4. Sherman ME, Bitterman P, Rosenshein N, Delgado G, Kurman RJ. Uterine serous carcinoma: a morphologically diverse neoplasm with unifying clinicopathologic features. Am J Surg Pathol 1992;16:600-10.

5. Levenback C, Burke TW, Silva E. Uterine papillary serous carcinoma (UPSC) treated with cisplatin, doxorubicin and cyclophosphamide (PAC). Gynecol Oncol 1992;46:317-21.

6. Sherman ME, Bur ME, Kurman RJ. p53 in endometrial cancer and its putative precursors: evidence for diverse pathways of tumorigenesis. Hum Pathol 1995;26:1268-74.

7. Moll MU, Chalas E, Auguste M, Meaney D, Chumas J. Uterine papillary serous carcinoma evolves via a p53-driven pathway. Hum Pathol 1996;27:1295-300.

8. Umesh M, Wolf D, Frossard PM. Ban II and Sca I RFLPs at the human p53 gene locus. Nucleic Acids Res 1988;16:775762.

9. Lane DP. p53 guardian of the genome. Nature 1993;358: $15-6$.

10. Hartwell LM, Kastan MB. Cell cycle control and cancer. Science 1994;266:1821-8.

11. Lowe SW, Ryley HE, Jacks T, Housman DE. p53 dependent apoptosis modulates the cytotoxicity of anticancer agents. Cell 1993;74:957-67.

12. Hollstein M, Sidransky D, Vogelstein B, Harris CC. p53 mutations in human cancers. Science 1991;253:49-53.

13. Chen Levy Z, Nourse J, Cleary ML. The bcl-2 candidate proto-oncogene is a 24-kilodalton integral-membrane protein highly expressed in lymphoid cell lines and lymphomas carrying the $\mathrm{t}(14: 18)$. Mol Cell Biol 1989;9:701-10.

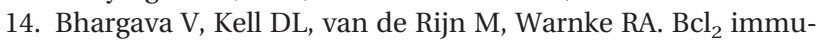
noreactivity in breast carcinoma correlates with hormone receptor positivity. Am J Pathol 1994;145:535-40.

15. McDonnell TS, Tronosco P, Brisbay SM, Logothetis C, Chung LWK, Hsieh JT, et al. Expression of the proto-oncogene $\mathrm{bcl}_{2}$ in the prostate and its association with emergence of androgen-independent prostate cancer. Cancer Res 1992;52: 6940-4.

16. Pezzela F, Turley H, Kuzu I, Tunkegar ME, Dunnil MS, Pierce $\mathrm{CB}$, et al. Bcl-2 protein in non-small cell lung carcinoma. N Engl J Med 1993;329:690-4.

17. Oltvai G, Milliman C, Korsmeyer S. Bcl-2 heterodimerizes in vivo with a conserved homolog Bax, that accelerates programmed cell death. Cell 1993;74:609-19.

18. Yin XM, Oltvai ZN, Korsmeyer SJ. BH1 and BH2 domains of bcl-2 are required for inhibition of apoptosis and heterodimerization with Bax. Nature 1994;369:321-33.

19. Miyashita T, Reed JC. Tumor suppressor p53 is a direct transcriptional activator of the human bax gene. Cell 1995; 80:293-9.

20. Miyashita T, Krajewski S, Krajewska M, Wang HG, Lin HK, Liebermann DA, et al. Tumor suppressor p53 is a regulator of bcl-2 and bax gene expression in vitro and in vivo. Oncogene 1994;9:1799-805.

21. Carcangiu ML, Chambers JT, Voynick IM, Pirro M, Schwartz PE. Immunohistochemical evaluation of estrogen and progesterone receptor content in 183 patients with endometrial carcinoma. Part I: clinical and histologic correlations. Am J Clin Pathol 1990;94:247-54.

22. Nyholm NCJ, Nielsen AL, Lynrup J, Norup P, Thorpe SM. Biochemical and immunohistochemical estrogen and progesterone receptors in adenomatous hyperplasia and endometrial carcinoma: correlation with stage and other clinicopathologic features. Am J Obstet Gynecol 1992;167:1334-42.

23. Li SF, Shiozawa T, Nakayama K, Nikaido T, Fujii S. Stepwise abnormality of sex steroid hormone receptors, tumor suppressor gene products (p53 and Rb) and cyclin E in uterine endometrioid carcinoma. Cancer 1996;77:321-9.

24. Kerr JF, Winterford CM, Harmon BV. Apoptosis: its significance in cancer and cancer therapy. Cancer 1994;73:201326.

25. Berchuck A, Kohler MF, Marks JR, Wiseman R, Boyd J, Bast RC Jr. The p53 tumor suppressor gene frequently is altered in gynecologic cancers. Am J Obstet Gynecol 1994;170:246-52.

26. Jiko K, Sasano H, Ito K, Orawa N, Sato S, Yajima A. Immunohistochemical and in situ hybridization analysis of p53 in human endometrial carcinoma of the uterus. Anticancer Res 1993;13:305-10.

27. Ambros RA, Vigna PA, Figge J, Kalakurry BVS, Mastrangelo A, Eastman AY, et al. Observation of tumor and metastatic suppressor gene status in endometrial carcinoma with particular emphasis on p53. Cancer 1994;731:1686-92.

28. Zheng W, Peiqin C, Zheng M, Kramer EE, Godwin TA. p53 overexpression and bcl-2 persistence in endometrial carcinoma: comparison of papillary serous and endometrioid subtypes. Gynecol Oncol 1996;61:167-74.

29. Bur ME, Perlman C, Edelmann BS, Fey E, Rose PG. p53 expression in neoplasms of the uterine corpus. Am J Clin Pathol 1992;98:81-7.

30. Inoue M, Fujita M, Enomoto T, Morimoto H, Monden T, Shinano T, et al. Immunohistochemical analysis and p53 in 
gynecologic tumors. Am J Clin Pathol 1994;102:665-70.

31. Prat J, Oliva E, Lerma E, Vaquero M, Matias-Guiu X. Uterine papillary serous adenocarcinoma: a 10-case study of p53 and c-erbB-2 expression and DNA content. Cancer 1994;74:1778-83.

32. Reinartz JS, George E, Undgren BR, Niehans GA. Expression of p53, transforming growth factor alpha, epidermal factor receptor and c-erbB-2 in endometrial carcinoma and correlation with survival and known predictors of survival. Hum Pathol 1994;25:1075-83.

33. Khalifa MA, Mannel RS, Haraway SD, Walker J, Min KW. Expression of EGFR, HER-2/neu, p53 and PCNA in endometrioid, serous papillary and clear cell endometrial adenocarcinomas. Gynecol Oncol 1994;53:84-92.

34. King SA, Adas A, Livolsi VA, Takahashi H, Behbakht $\mathrm{K}$, McGovern P, et al. Expression and mutation analysis of the p53 gene in uterine papillary serous carcinoma. Cancer 1995; 75:2700-5.

35. Tashiro H, Isacson C, Levine R, Kurman RJ, Cho KR, Hedrick L. p53 gene mutations are common in uterine serous carcinoma and occur early in their pathogenesis. Am J Pathol 1997;150:177-85.

36. Soslow RA, Shen PUF, Chung MH, Isacson C. Distinctive p53 and $\mathrm{mdm} 2$ immunohistochemical expression profiles suggest different pathogenetic pathways in poorly differentiated endometrial carcinoma. Int J Gynecol Pathol 1998;17:12934 .

37. Kounelis S, Jones MW, Papadaki H, Bakker A, Swalsky P, Finkelstein SD. Carcinosarcomas (malignant mixed mullerian tumors) of the female genital tract: comparative molecular analysis of epithelial and mesenchymal components. Hum Pathol 1998;29:82-7.

38. Domagala W, Harezga B, Szadowska A, Markiewski M, Weber K, Osborn M. Nuclear p53 protein accumulates preferentially in medullary and high-grade ductal but rarely in lobular breast carcinomas. Am J Pathol 1993;142:669-74.

39. Risinger JI, Dent GA, Ingar-Trowbridge D, McLachlen JA, Tsao MS, Senterman M, et al. p53 gene mutations in human endometrial carcinoma. Mol Carcinog 1992;5:250-3.

40. Enomoto T, Fujita M, Inoue M, Rice JM, Nakajima R, Tanizawa $\mathrm{O}$, et al. Alterations of the p53 tumor suppressor gene and its association with activation of c-K-ras-2 protooncogene in premalignant and malignant lesions of the human uterine endometrium. Cancer Res 1993;53:1883-8.

41. Ambros RA, Ross JS, Kallakury BVS, Malfetano J, Kim Y, Hwang J, et al. p53 gene status in endometrial carcinomas showing diffuse positivity for p53 protein by immunohistochemical analysis. Mod Pathol 1995;8:441-5.

42. Ambros RA, Sheehan CE, Kallakury BVS, Ross JS, Malfetano J, Paunovich E, et al. Mdm2 and p53 protein expression in the histologic subtypes of endometrial carcinoma. Mod Pathol 1996;9:1165-9.

43. Kohler MF, Nishii H, Humphrey PA, Saski H, Marks J, Bast RC, et al. Mutation of the p53 tumor suppressor gene is not a feature of endometrial hyperplasias. Am J Obstet Gynecol 1993;169:600-94.

44. Ito K, Watanabe K, Nasim S, Sasano H, Sato S, Yajima A, et al. Prognostic significance of p53 overexpression in endometrial cancer. Cancer Res 1994;54:4667-70.

45. Hamel WW, Sebo TJ, Wilson TO, Keeney GL, Roche PC, Suman VJ, et al. Prognostic value of p53 and proliferating cell nuclear antigen expression in endometrial carcinoma. Gynecol Oncol 1996;62:192-8.

46. Riethdorf L, Begemann C, Riethdorf S, Langosch KM, Loning T. Comparison of benign and malignant endometrial lesions for their p53 state, using immunohistochemistry and temperature-gradient gel electrophoresis. Virchows Arch 1996;428:47-51.

47. Yamauchi N, Sakamoto A, Uozaki H, Iihara K, Machinami R.
Immunohistochemical analysis of endometrial adenocarcinoma for bcl-2 and p53 in relation to expression of sex steroid receptor and proliferative activity. Int J Gynecol Pathol 1996;15:202-8.

48. Spiegel GW. Endometrial carcinoma in situ in postmenopausal women. Am J Surg Pathol 1995;19:417-32.

49. Ambros RA, Sherman ME, Zahn CM, Bitterman P, Kurman RJ. Endometrial intraepithelial carcinoma: a distinctive lesion specifically associated with tumors displaying serous differentiation. Hum Pathol 1995;26:1260-7.

50. Reed JC. Bcl-2 and the regulation of programmed cell death. J Cell Biol 1994;124:1-6.

51. Lu QL, Abel P, Foster CS, Lalani E. bcl-2: role in epithelial differentiation and oncogenesis. Hum Pathol 1996;27:10210.

52. Gompel A, Sabourin JC, Martin A, Yaneva H, Audouin J, Decroix $\mathrm{Y}$, et al. bcl-2 expression in normal endometrium during the menstrual cycle. Am J Pathol 1994;144:1195-202.

53. Chan WK, Mole MM, Levison DA, Ball RY, Lu QL, Patel K, et al. Nuclear and cytoplasmic bcl-2 expression in endometrial hyperplasia and adenocarcinoma. J Pathol 1995;177:241-6.

54. Henderson GS, Brown KA, Perkins SL, Abbott TM, Clayton F. bcl-2 is down regulated in atypical endometrial hyperplasia and adenocarcinoma. Mod Pathol 1996;9:430-8.

55. Chhieng DC, Ross JS, Ambros RA. bcl-2 expression and the development of endometrial carcinoma. Mod Pathol 1996;9: 402-6.

56. Taskin M, Lallas TA, Barber HRK, Shevchuk MM. bcl-2 and p53 in endometrial adenocarcinoma. Mod Pathol 1997;10: 728-34.

57. Coppola D, Fu L, Nicosia SV, Kounelis S, Jones M. Prognostic significance of p53, bcl-2, vimentin and S-100 proteinpositive Langerhans cells in endometrial carcinoma. Hum Pathol 1998;29:455-62.

58. Niemann TH, Trgovac TL, McGaughy VR, Vaccarello L. bcl-2 expression in endometrial hyperplasia and carcinoma. Gynecol Oncol 1996;63:318-22.

59. Krajewski S, Krajewska M, Shabaik A, Miyashita T, Wang HG, Reed JC. Immunohistochemical determination of in vivo distribution of bax: a dominant inhibitor of bcl-2. Am J Pathol 1994;145:1323-36.

60. Sarbia M, Bittinger F, Grabellus F, Verreet P, Dutrowski P, Willers R, et al. Expression of bax, a proapoptotic member of the bcl-2 family in esophageal squamous cell carcinoma. Int J Cancer 1997;73:508-13.

61. Krajewska M, Krajewski S, Epstein J, Shabaik A, Sauvageot J, Song K, et al. Immunohistochemical analysis of bcl-2, bax, bcl-x and mcl-1 expression in prostate cancers. Am J Pathol 1996;148:1567-76.

62. Krajewska M, Fenoglio-Preiser CM, Krajewski S, Song K, Macdonald JS, Stemmerman G, et al. Immunohistochemical analysis of bcl-2 family proteins in adenocarcinomas of the stomach. Am J Pathol 1996;149:1449-57.

63. Krajewski S, Blomqvist C, Franssila K, Krajewska M, Wasenius VM, Niskanen E, et al. Reduced expression of proapoptotic gene bax is associated with poor response rates to combination chemotherapy and shorter survival in women with metastatic breast adenocarcinoma. Cancer Res 1995;55: 4471-8.

64. Kapranos N, Karaiosifidi H, Valavanis G, Kouri E, Vasilaros S. Prognostic significance of apoptosis related proteins bcl-2 and bax in node-negative breast cancer patients. Anticancer Res 1997;17(4A):2499-505.

65. Krajewska M, Moss SF, Krajewski S, Song K, Holt PP, Reed JC. Elevated expression of bcl-x and reduced bak in primary colorectal adenocarcinomas. Cancer Res 1996;56:2422-7.

66. Brambilla E, Negoescu A, Gazzeri S, Lantuejoul S, Moro D, Brambilla C, et al. Apoptosis-related factors p53, bcl-2 and 
bax in neuroendocrine lung tumors. Am J Pathol 1996;149: 1949-52.

67. Umpiere SA, Burke TW, Tornos C, Ordonez N, Levenback C, Morris M. Immunohistochemical analysis of uterine papillary serous carcinomas for estrogen and progesterone receptors. Int J Gynecol Pathol 1994;13:127-30.

68. Nanbu K, Konishi J, Komatsu T, Mandai M, Yamamoto S, Kurada $\mathrm{H}$, et al. Expression of heat shock proteins HSP70 and HSP90 in endometrial carcinomas: correlation with clinicopathology, sex steroid receptor status and p53 protein expression. Cancer 1996;77:330-8.

69. Bergeron G, Ferenczy A, Shyamala G. Distribution of estro- gen receptors in various cell types of normal, hyperplastic, and neoplastic human endometrial tissues. Lab Invest 1998; 58:338-45.

70. Zaino RJ, Sartwaswaroop PG, Mortel R. The relationship of histologic parameters to progesterone receptor status in endometrial adenocarcinoma. Gynecol Oncol 1983;16: 196-208.

71. Creasman WT. Prognostic significance of hormone receptors in endometrial cancer. Cancer 1993;71(Suppl):146770 .

72. Rose PG. Endometrial carcinoma. N Engl J Med 1996;335: 640-9.

\section{Book Review}

\section{Fenoglio-Preiser CM, Noffsinger AE, Stemmer- mann GN, Lantz PE, Listrom MB, Rilke FO: Gastrointestinal Pathology Plus on CD- ROM, Philadelphia, Lippincott Williams \& Wilkins, 1999 (\$350).}

The second edition of Gastrointestinal Pathology is now available on CD-ROM. The electronic version contains an expanded text and more illustrations. It runs under Windows or Macintosh operating systems and requires at least $8 \mathrm{MB}$ of RAM. I have run it on Windows 95, 98, and NT. Installation notes recommend setting virtual memory at $20 \mathrm{MB}$ or greater for optimal pictorial quality. A good rule of thumb is to set virtual memory at twice the amount of RAM, but keep in mind that Windows prefers to self-manage virtual memory for most applications. The production disk contains $270 \mathrm{MB}$ of data, with approximately $85 \%$ of the space devoted to pictures and diagrams. A combination of software products are bundled together to run this reference work. The vendors include Folio Corporation for text retrieval and Iterated Systems for image display.

Navigation around the disk is easy at the top level but awkward when paging through individual chapters. There are shortcuts to individual topics via the Go To option, but one needs to enter a numerical address. Hyperlinks to pictures and illustrations allow you to overlay windows for side-by-side comparisons with the written text, and there is a clever pop-up option to view immediately any cited reference. An effective search engine that uses Boolean logic is available for names or key words, and there are shortcuts to jump to your results. Instructions on printing text items and exporting images are available in the Read Me files. Overall, this disk contains sufficient tools to keep most users occupied for a long time.

The text and illustrations have been revised for the second edition, and references are updated through 1995 (some through 1996). A selective review of dysplasia in ulcerative colitis shows it to be clear, concise, and complete. The recommendations for dysplasia-associated lesions or masses are practical. The section on gastritis generally follows the Sydney System with the usual caveats. However, I was disappointed not to find the 1996 article by Dixon et $a l$. concerning the updated principles and grading data. A discussion of gastroesophageal reflux disease, 24-h acid testing, and short-segment Barrett esophagus is lacking. Gross photographs, radiographs, and diagrams are of excellent quality. Unfortunately, photomicrographs appear pixelated and rapidly degraded when zoomed.

The combination of content, search capabilities, and the ability to print text and export images makes this $\mathrm{CD}$ a powerful reference work. The one disadvantage of this format is the quality of the photomicrographs. Keeping in mind that the capacity of an ordinary 75-cent disk is 650 $\mathrm{MB}$ and the availability of file compression technology, one would think that medical publishers could produce higher quality microscopic images.

Peter A. McCue

Thomas Jefferson University

Philadelphia, Pennsylvania 